\title{
Species-specificity of the glutathione reduced form accumulation in the arboreal plants, testing influence of industrial emissions
}

\author{
Dmitry Syshchykov \\ Plant Physiology and Soils Biology Department, Kryvyi Rig Botanical Garden NAS of Ukraine, 50, Marshaka str., \\ Kryvyi Rig, 50089, Ukraine, e-mail: 2007dmitry@ rambler.ru
}

Keywords: glutathione, arboreal plants, industrial contamination, assimilatory apparatus

\section{SUMMARY}

Conducted are researches of dynamics of glutathione reduced form maintenance in the leaves of arboreal plants which grow in the zones of different level of contamination by industrial emissions of "Red Lead Factory" LTD and ArselorMittal Kryvyi Rig. For comparison, similar investigations were conducted in the intact Botanic Garden in s.c.t. Sofievka. Findings testify to absence of negative influence of industrial emissions and, thus, the arboretum of botanical garden also can be examined as conditional control. It was stated that it is set a few strategies of active oxygen forms and their metabolites deactivation, appearing in cells under action of environment negative factors. To our opinion, fluctuation of glutathione reduced form maintenance can examine as an index of plants stability, on which investigational species can be distributed on steady and moderato steady.

\section{INTRODUCTION}

Presently contamination of environment industrial extrass is consider as a new ecological factor, thus heavy metals are one of most dangerous pollutants (Usmanov et al., 2001). In spite of their very small maintenance in an organism, they substantially influence on the exchange of matters and growth processes, that results in general, physiological and biochemical changes (Bishnoi et al., 1993; Moral et al., 1994).

In forming of antioxidant status of plant organism along with such known antioxidants, as ascorbic acid and tocopherols active voice is accepted by the endogenous antioxidant glutathione (Strohm et al., 1995). Along with implementation of row functions in plant organism, such as participating in the processes of sulfur transport and metabolism, synthesis of proteins and DNA, regulation of enzymes activity, an important role belongs to the glutathione reduced form in the biochemical processes of cells defense from oxidative stress, induced by various abiotic factors and is one of the first reactions of organism on the action of toxic compounds and in particular heavy metals (Hippeli - Elstner, 1996; Vladimirov - Archakov, 1972)

However, in spite of widely described in literature antioxidative function of glutathione (Kangasjarvi at al., 1994; Noctor et al., 1998; Platonova et al., 1998), its maintenance at the action of emissions of industrial enterprises remains it is not enough studied, what was the aim of our work.

\section{MATERIALS AND METHODS}

The objects of researches were followings species of arboreal plants Populus bolleana Lauche, P. italica Moench., Tilia cordata Mill., Aesculus hippocastanum L., Picea pungens Engelm., Sorbus aucuparia L., Betula pendula Roth. and Acer negundo L. For determination of the glutathione reduced form maintenance leaves and pine-needle were taken away from 1-2 summer shoots of identical tier and exposition.

The concentration of the glutathione reduced form was determined by the method of Beutler et al. (1963), modified by us. Basis of method is ability of glutathione reduced form SH-group to co-operate with 5.5-ditiobis2-nitrobenzoic acid (Ellman's reagent) with formation of 2-nitro-6-mercaptobenzoic acid. Intensity of solution painting is proportional glutathione maintenance in a probe (Gryshko - Syshchykov, 2002).

For determination of the glutathione reduced form used $20 \%$ homogenate of plants tissues, prepared on $0.3 \mathrm{M} \mathrm{dm}^{-3} \mathrm{~K}-\mathrm{P}$ buffer with $\mathrm{pH}$-value of 7.5 (relation tissue/buffer - 1/5). Received homogenate was centrifuged for $20 \mathrm{~min}$ at $4000 \mathrm{~g}$. To $2 \mathrm{~cm}^{3}$ of supernatant added $3 \mathrm{~cm}^{3}$ of besieging reagent (in $100 \mathrm{~cm}^{3}$ of which contained a $1.67 \mathrm{~g}$ of $\mathrm{HPO}_{3}, 0.2 \mathrm{~g}$ of EDTA, $30 \mathrm{~g}$ of NaCl ) and conducted a re-centrifugation during $10 \mathrm{~min}$ at $4000 \mathrm{~g}$. Further in a cuvette with $1 \mathrm{~cm}$ optical way length of brought in $2 \mathrm{~cm}^{3} 0.3 \mathrm{M} \mathrm{dm}$ K-P buffer, $0.05 \mathrm{~cm}^{3}$ of $1 \mathrm{mM} \mathrm{dm}^{-3}$ solution of Ellman's reagent, $2 \mathrm{~cm}^{3}$ of the received supernatant and conducted measuring of absorbance at $412 \mathrm{~nm}$ on a spectrophotometer type SF 2000 (Russia). From data of homogenates absorbance measuring and on a gauge curve determined the concentration of the glutathione reduced form. Maintenance of last $\left(\mathrm{G}, \mathrm{mM} \mathrm{g}^{-1}\right.$ of raw matter) expected by formula:

$$
\mathrm{G}=\mathrm{c} / \mathrm{Mr} \times \mathrm{K}
$$

where: $\mathrm{c}$ - glutathione concentration $\left(\mathrm{mg} \mathrm{cm}^{3}\right), \mathrm{Mr}-$ glutathione relative molecular mass (307.3), $\mathrm{K}-$ coefficient of re-calculation on one gram of raw matter $(K=5)$. For the construction of gauge curve used standard solutions of the glutathione reduced form (Gryshko - Syshchykov, 2002). 


\section{RESULTS AND DISCUSSION}

The conducted researches of the glutathione reduced form accumulation by leaves of Populus bolleana allowed to set that at plants, sprouting on territory of arboretum of the Kryvyi Rig botanical garden, its concentration in the phase of complete isolation of leaf did not differ from the last at the plants of s.c.t. Sofievka. On monitoring areas, located in the zones of action of industrial emissions "Red Lead Factory" LTD, in the zone of strong contamination intensity of oxidizing processes in cells increased, what had resulted in the statistically reliable increase of antioxidant maintenance on $35 \%$ in relation to conditional control (arboreal plants, sprouting in s.c.t. Sofievka). Findings and researches of Smith et al. (1990) allow us to use the values of glutathione reduced form concentration as a sensible marker of a stress influence and relative index of stability of plants. In the zone of weak contamination of the noted enterprise the concentration of the explored tri-peptide did not differ from control (Table 1).

In the $P$. bolleana assimilatory apparatus on the areas of strong contamination (flattings mills and blastfurnace № 9) of ArselorMittal Kryvyi Rig maintenance of the glutathione reduced form more than on $40 \%$ exceeded control indexes. The resulted information testifies to the considerable activating of the glutathione antioxidative system by the acceleration of functioning of antioxidant oxidization-reduction cycle by the proper glutathione dependent enzymes and probable intensification of its synthesis de novo. Together with it, statistically reliable difference in the glutathione accumulation in $P$. bolleana leaves on the monitoring areas of zones of strong contamination "Red Lead Factory" LTD and ArselorMittal Kryvyi Rig was not set. In the zone of weak contamination, as well as on the monitoring area of "Red Lead Factory" LTD, maintenance of tripeptide did not differ from control.

In the phase of completion of development and ripening of $P$. bolleana leaf a general tendency was glutathione reduced form concentration growth on 6-30\% on all of monitoring areas as compared to the first phase of plants assimilatory apparatus development. As well as in the previous variant of researches, maintenance of the explored tripeptide increased on 30-40\% in the zone of strong contamination and statistically did not differ from control indexes in the zones of weak contamination and in the arboretum of the Kryvyi Rig botanical garden (table).

In the leaves of other representative of Populus genus - Populus italica in a phase of leaf complete isolation is saved tendency to intensification of glutathione dependent anti-oxidative system functioning in the conditions of contamination the extrass of industrial enterprises, that is expressed in growth of explored tripeptide concentration on the average in 1.4 time on the monitoring areas of zones of strong contamination "Red Lead Factory" LTD and ArselorMittal Kryvyi Rig as compared to the analogical plants indexes in s.c.t. Sofievka. Receive by us information is confirmed the results of researches of Kunert and Hofer (1987), which rotined that the glutathione concentration rose in the leaves of poplars, growing's near to motorways with high-density of movement. On other experimental areas, as well as at previous specie, maintenance of antioxidant statistically did not differ from control (Table 1). It is necessary also to mark that concentration of the glutathione reduced form in the leaves of $P$. italica on all of monitoring areas was below, than at a P. bolleana.

Resulted in a table information allow to establish that in the phase of completion of development and ripening of leaf maintenance of antioxidant in the leaves of $P$. italica, unlike a previous specie, increased signficantly anymore (in 1.3-1.9 times). However a tendency in relation to intensification of glutathione reduced form accumulation in the assimilatory apparatus of plants at the substantial level of industrial emissions was saved. So, in the zones of strong contamination "Red Lead Factory" LTD and ArselorMittal Kryvyi Rig maintenance of tripeptide exceeded control values on 24-37\%. On other monitoring areas statistically reliable difference in the antioxidant accumulation was not set.

In leaves other, from literary data (Bessonova, 2006; Ilkun, 1978), steady specie - Acer negundo, is marked other strategy of deactivation of oxygen active forms and their metabolites, appearing in cells under the action of negative factors of environment. At this specie both in the phase of complete isolation of leaf and in the phase of completion of development and ripening of leaf it was not set statistically reliable difference of glutathione reduced form maintenance in an assimilatory apparatus on all monitoring areas (Table 1). Findings, probably, testify exactly to considerable intensification of the explored tripeptide reutilization, but not about its active synthesis. Confirmation of possible narrow-mindedness of glutathione synthesis is and fact of decline of its maintenance in leaves on $15-40 \%$ in the second phase of researches.

Analysis of data in relation to the glutathione reduced form accumulation in a pine-needle of Picea pungens rotined that in a phase began the isolations of pine-needle maintenance of last does not differ from control practically on all monitoring areas. Only in the zone of weak contamination "Red Lead Factory" LTD is marked growth of antioxidant concentration on $40 \%$. Findings can testify that at the strong level of contamination the overwhelming amount of the glutathione reduced form is used in the conjugational reactions of stress influence intermediates detoxication (phytochelatins formation, hydro- and lypoperoxides conjugation with participation of glutathione-S-transferase and other) and only at moderate intensity of the technogenic loading there is certain "reserve" of antioxidant. 
Table 1.: Glutathione reduced form concentrations ( $\mathrm{mM} \mathrm{g}^{-1}$ fresh weight) in leaves of arboreal plants

\begin{tabular}{|c|c|c|c|c|}
\hline \multirow{2}{*}{ Monitoring area } & \multicolumn{2}{|c|}{$\mathrm{I}$} & \multicolumn{2}{|c|}{ II } \\
\hline & $\mathrm{M} \pm \mathrm{m}$ & $\mathrm{T}_{\mathrm{st}}$ & $\mathrm{M} \pm \mathrm{m}$ & $\mathrm{T}_{\mathrm{st}}$ \\
\hline \multicolumn{5}{|c|}{ Populus bolleana Lauche } \\
\hline s.c.t. Sofievka & $29.1 \pm 0.62$ & - & $33.1 \pm 1.5$ & - \\
\hline Arboretum of Kryvyi Rig Botanical Garden & $31.7 \pm 2.83$ & 0.91 & $33.4 \pm 0.97$ & 0.17 \\
\hline "Red Lead Factory" LTD (zone of strong contamination) & $39.2 \pm 1.59$ & 5.94 & $46.3 \pm 2.9$ & 4.01 \\
\hline "Red Lead Factory" LTD (zone of weak contamination) & $30.3 \pm 1.42$ & 0.84 & $35.8 \pm 1.53$ & 1.26 \\
\hline ArselorMittal Kryvyi Rig (zone of strong contamination) 1 & $41.0 \pm 0.76$ & 12.19 & $44.3 \pm 0.86$ & 6.45 \\
\hline ArselorMittal Kryvyi Rig (zone of strong contamination) 2 & $41.8 \pm 1.41$ & 8.26 & $47.4 \pm 1.11$ & 7.64 \\
\hline ArselorMittal Kryvyi Rig (zone of weak contamination) & $27.5 \pm 1.26$ & 1.1 & $35.9 \pm 1.75$ & 1.19 \\
\hline \multicolumn{5}{|c|}{ P. italica Moench. } \\
\hline s.c.t. Sofievka & $20.0 \pm 0.51$ & - & $36.9 \pm 0.79$ & - \\
\hline Arboretum of Kryvyi Rig Botanical Garden & $18.3 \pm 1.12$ & 1.37 & $35.6 \pm 1.55$ & 0.74 \\
\hline "Red Lead Factory" LTD (zone of strong contamination) & $28.3 \pm 1.54$ & 5.14 & $47.2 \pm 1.4$ & 6.4 \\
\hline "Red Lead Factory" LTD (zone of weak contamination) & $20.9 \pm 1.49$ & 0.56 & $40.2 \pm 1.62$ & 1.84 \\
\hline ArselorMittal Kryvyi Rig (zone of strong contamination) 1 & $32.8 \pm 1.23$ & 9.63 & $50.7 \pm 2.66$ & 4.97 \\
\hline ArselorMittal Kryvyi Rig (zone of strong contamination) 2 & $35.4 \pm 1.95$ & 7.65 & $45.6 \pm 2.34$ & 3.53 \\
\hline ArselorMittal Kryvyi Rig (zone of weak contamination) & $22.3 \pm 1.4$ & 1.58 & $36.5 \pm 2.31$ & 0.15 \\
\hline \multicolumn{5}{|c|}{ Acer negundo L. } \\
\hline s.c.t. Sofievka & $44.5 \pm 2.97$ & - & $28.6 \pm 1.51$ & - \\
\hline Arboretum of Kryvyi Rig Botanical Garden & $42.3 \pm 1.47$ & 0.66 & $31.5 \pm 1.12$ & 1.51 \\
\hline "Red Lead Factory" LTD (zone of strong contamination) & $45.3 \pm 2.39$ & 0.21 & $27.8 \pm 0.59$ & 0.5 \\
\hline "Red Lead Factory" LTD (zone of weak contamination) & $41.2 \pm 2.57$ & 0.85 & $31.3 \pm 1.6$ & 1.21 \\
\hline ArselorMittal Kryvyi Rig (zone of strong contamination) 1 & $48.5 \pm 2.88$ & 0.96 & $28.7 \pm 0.41$ & 0.05 \\
\hline ArselorMittal Kryvyi Rig (zone of strong contamination) 2 & $44.8 \pm 0.99$ & 0.11 & $30.8 \pm 0.55$ & 1.36 \\
\hline ArselorMittal Kryvyi Rig (zone of weak contamination) & $38.4 \pm 2.15$ & 1.66 & $32.9 \pm 1.71$ & 1.88 \\
\hline \multicolumn{5}{|c|}{ Picea pungens Engelm. } \\
\hline s.c.t. Sofievka & $9.5 \pm 0.59$ & - & $6.8 \pm 0.27$ & - \\
\hline Arboretum of Kryvyi Rig Botanical Garden & $11.0 \pm 0.68$ & 1.67 & $7.6 \pm 0.44$ & 1.65 \\
\hline "Red Lead Factory" LTD (zone of strong contamination) & $10.2 \pm 0.34$ & 0.96 & $7.4 \pm 0.61$ & 0.93 \\
\hline "Red Lead Factory" LTD (zone of weak contamination) & - & - & - & - \\
\hline ArselorMittal Kryvyi Rig (zone of strong contamination) 1 & - & - & - & - \\
\hline ArselorMittal Kryvyi Rig (zone of strong contamination) 2 & $10.5 \pm 0.3$ & 1.48 & $7.8 \pm 0.39$ & 2.09 \\
\hline ArselorMittal Kryvyi Rig (zone of weak contamination) & $13.3 \pm 0.29$ & 5.79 & $9.1 \pm 0.4$ & 4.85 \\
\hline \multicolumn{5}{|c|}{ Tilia cordata Mill. } \\
\hline s.c.t. Sofievka & $15.6 \pm 1.36$ & - & $47.6 \pm 2.81$ & - \\
\hline Arboretum of Kryvyi Rig Botanical Garden & $17.8 \pm 1.3$ & 1.16 & $45.1 \pm 2.86$ & 0.64 \\
\hline "Red Lead Factory" LTD (zone of strong contamination) & $40.5 \pm 2.39$ & 9.08 & $42.4 \pm 2.88$ & 1.3 \\
\hline "Red Lead Factory" LTD (zone of weak contamination) & - & - & - & - \\
\hline ArselorMittal Kryvyi Rig (zone of strong contamination) 1 & - & - & - & - \\
\hline ArselorMittal Kryvyi Rig (zone of strong contamination) 2 & $33.7 \pm 1.31$ & 9.6 & $38.7 \pm 1.84$ & 2.64 \\
\hline ArselorMittal Kryvyi Rig (zone of weak contamination) & - & - & - & - \\
\hline \multicolumn{5}{|c|}{ Sorbus aucuparia $\mathrm{L}$. } \\
\hline s.c.t. Sofievka & $39.6 \pm 1.48$ & - & $45.2 \pm 3.43$ & - \\
\hline Arboretum of Kryvyi Rig Botanical Garden & $37.5 \pm 1.96$ & 0.86 & $48.6 \pm 2.29$ & 0.82 \\
\hline "Red Lead Factory" LTD (zone of strong contamination) & $34.4 \pm 1.36$ & 2.55 & $34.6 \pm 2.25$ & 2.59 \\
\hline "Red Lead Factory" LTD (zone of weak contamination) & - & - & - & - \\
\hline ArselorMittal Kryvyi Rig (zone of strong contamination) 1 & - & - & - & - \\
\hline ArselorMittal Kryvyi Rig (zone of strong contamination) 2 & $28.6 \pm 2.11$ & 4.27 & $21.2 \pm 1.25$ & 6.58 \\
\hline ArselorMittal Kryvyi Rig (zone of weak contamination) & - & - & - & - \\
\hline \multicolumn{5}{|c|}{ Aesculus hippocastanum L. } \\
\hline s.c.t. Sofievka & $25.3 \pm 1.62$ & - & $87.1 \pm 4.26$ & - \\
\hline Arboretum of Kryvyi Rig Botanical Garden & $27.5 \pm 0.9$ & 1.2 & $85.0 \pm 6.94$ & 0.26 \\
\hline "Red Lead Factory" LTD (zone of strong contamination) & $31.3 \pm 2.57$ & 1.97 & $61.0 \pm 5.65$ & 3.68 \\
\hline "Red Lead Factory" LTD (zone of weak contamination) & - & - & - & - \\
\hline ArselorMittal Kryvyi Rig (zone of strong contamination) 1 & - & - & - & - \\
\hline ArselorMittal Kryvyi Rig (zone of strong contamination) 2 & $29.7 \pm 0.83$ & 2.45 & $42.8 \pm 2.75$ & 8.73 \\
\hline ArselorMittal Kryvyi Rig (zone of weak contamination) & - & - & - & - \\
\hline \multicolumn{5}{|c|}{ Betula pendula Roth. } \\
\hline
\end{tabular}




\begin{tabular}{|l|c|c|c|c|}
\hline s.c.t. Sofievka & $43.1 \pm 2.24$ & - & $93.4 \pm 4.2$ & - \\
\hline Arboretum of Kryvyi Rig Botanical Garden & $40.7 \pm 1.58$ & 0.9 & $94.2 \pm 3.96$ & 0.13 \\
\hline "Red Lead Factory" LTD (zone of strong contamination) & $52.0 \pm 2.72$ & 2.51 & $63.6 \pm 4.26$ & 4.99 \\
\hline "Red Lead Factory" LTD (zone of weak contamination) & - & - & - & - \\
\hline ArselorMittal Kryvyi Rig (zone of strong contamination) 1 & $32.0 \pm 1.91$ & 3.78 & $47.8 \pm 3.28$ & 8.56 \\
\hline ArselorMittal Kryvyi Rig (zone of strong contamination) 2 & - & - & - & - \\
\hline ArselorMittal Kryvyi Rig (zone of weak contamination) & - & - & - & - \\
\hline
\end{tabular}

Note: I - phase of complete isolation of leaf (for a P. pungens - beginning of pine-needle isolation), II - phase of completion of development and ripening of leaf (for a $P$. pungens - complete of pine-needle isolation), - specie does not grows

In the phase of complete isolation of pine-needle the marked higher tendency of the explored tripeptide accumulation was saved. It is necessary to note the presence of certain decline of glutathione concentration (on $35-45 \%$ ) by comparison to the previous stage of researches (Table 1). In addition, antioxidant maintenance in a pine-needle was the lowest among all investigational species. Received by us information well conform to the results of other researchers which are fix relatively low maintenance of the glutathione reduced form at coniferous as compared to other arboreal plants and can testify to narrow-mindedness of its pool at stress conditions (Polle, 1996; Schupp - Rennenberg, 1988; Taulavuori, 1999).

Conducted researches of degree of glutathione accumulation in the leaves of Tilia cordata it was allowed to set that in the phase of complete isolation of leaf antioxidant maintenance statistically increased in 2.2-2.6 times on monitoring areas, located in the zones of strong contamination industrial emissions of "Red Lead Factory" LTD and ArselorMittal Kryvyi Rig, while in the arboretum of the Kryvyi Rig botanical garden - did not differ from control. Together with it, concentration of the explored tripeptide in the assimilatory apparatus of $T$. cordata was higher in the zone of strong contamination "Red Lead Factory" LTD by comparison to an area, located near to a 9 blast-furnace of ArselorMittal Kryvyi Rig (Table 1). Probably, the noted specificity of glutathione accumulation cans the explained by the spectrum of contaminants in emissions of two enterprises.

On the next stage of researches there is some other tendency of antioxidant distributing in leaves, testifying to outspend of glutathione pool at stress conditions. So, if their concentration in control, by comparison to the phase of complete isolation of leaf, grew in 2.5-3 times that at the action of toxic ingredients of industrial extrass does not differ from the analogical variants of experiments. Also in the zone of strong contamination "Red Lead Factory" LTD maintenance of antioxidant does not differ from control, and on the monitoring area of ArselorMittal Kryvyi Rig goes down. Thus, taking into account widely described in literature the important role of glutathione in the processes of anti-oxidative defense (del Rio, 2002; Foyer, 1997; Noctor, 2002), received by us data allow to take a $T$. cordata to the group moderato steady species.

Resulted in a table information allow to assert that in the phase of complete isolation of leaf at the strong level of contamination of "Red Lead Factory" LTD and ArselorMittal Kryvyi Rig concentration of the glutathione reduced form in the assimilatory apparatus of Sorbus aucuparia goes down on 13-28\% by comparison to control. On the next stage of researches, is marked the strengthening of cells redox equilibrium displacement toward activation of oxidization processes certificate what is a further decline of the explored tripeptide maintenance (on 24-53\%). It is necessary also to mark that as well as at previous specie, more substantial decline of glutathione concentration was observed on a monitoring area in the zone of strong contamination of ArselorMittal Kryvyi Rig. Probably in the leaves of S. aucuparia the glutathionedependent antioxidative system is second-rate in the processes of a stress influence intermediates defusing, and the glutathione synthesis practically does not take a place about what testifies the absence of statistically reliable difference in its accumulation phase-to-phase development of leaves.

In the assimilatory apparatus of Aesculus hippocastanum in a phase complete isolation of leaf there is a tendency of distributing of the glutathione reduced form analogical resulted for previous specie (Table 1). It is necessary to mark that in the zone of strong contamination "Red Lead Factory" LTD maintenance of antioxidant did not differ from control, while on the analogical area of ArselorMittal Kryvyi Rig increased (on 17\%).

In the phase of complete isolation of leaf is marked the general tendency of substantial increase of the explored tripeptide concentration (in 1.4-3.4 time) on all monitoring areas. However at plants which grow in the zones of strong contamination, intensity of the glutathione dependent anti-oxidative system functioning appeared low, by a certificate what a decline of antioxidant concentration on 30-50\% in relation to control (Table 1). Taking into account growth of glutathione maintenance on absolute values by comparison to the previous stage of researches in this case it is possible to assume the low level of expression the genome of glutathione reductase. To our opinion, the resulted fluctuations of the glutathione reduced form maintenance can be considered as an index relatively low stability of $A$. hippocastanum to a stress influence.

Analysis resulted in table information showed specificity of the proper reaction of the glutathionedependent system of assimilatory apparatus of Betula pendula on technogenic contamination. So, on the first stage of researches on a monitoring area in the zone of strong contamination of "Red Lead Factory" LTD the glutathione concentrations increased on $20 \%$, while at plants, sprouting in the zone of action of emissions of ArselorMittal Kryvyi Rig, - went down on $25 \%$. The resulted tendency of antioxidant accumulation to our opinion cans described by both different intensity of formation of lipids peroxidation products and spectrum of contaminants, in the industrial extrass of two enterprises. 
The maintainance of primary tendency towards increasing of the glutathione reduced form concentration in the phase of complete isolation of leaf is also marked and in the assimilatory apparatus of $B$. pendula. It should be noted that although among investigational species the last had the greatest absolute indexes of antioxidant maintenance, it was not set the probable activating of glutathione dependent anti-oxidative system functioning. So, glutathione reduced form concentration in the leaves of B. pendula on monitoring areas, located in the zones of strong technogenic contamination "Red Lead Factory" LTD and ArselorMittal Kryviy Rig went down in 1.5-2 times accordingly. Together with it, noted more low level of antioxidant in the leaves of B. pendula on the monitoring area of ArselorMittal Kryviy Rig is observed and in this phase of development of assimilatory apparatus of plants.

\section{CONCLUSIONS}

Thus, it is possible to establish as a result of the conducted researches, that the on maintenance of glutathione reduced form plants of arboretum of the Kryvyi Rig botanical garden in both phases of assimilatory apparatus development does not differ from analogical, sprouting in s.c.t. Sofievka. Findings testify to absence of negative influence of industrial emissions and, thus, the arboretum of botanical garden also can be examined as conditional control. Also we are mark a few strategies of oxygen active forms and their metabolites deactivation, appearing in cells under action of negative factors of environment. One of them is intensification of glutathione reduced form accumulation in the conditions of industrial contamination, probably due to the acceleration of its synthesis. Second is stabilizing of antioxidant maintenance at the control level for the account of activating of functioning of enzymes of its reduction (glutathione- and ascorbate dependent reductase enzymes). According to our opinion, fluctuation of glutathione reduced form maintenance can examine as an index of plants stability of, on which investigational species can be distributed on steady and moderato steady. To the first group belong Populus bolleana, Populus italica, Picea pungens and Acer negundo, to the second - Tilia cordata, Sorbus aucuparia, Aesculus hippocastanum, at which, probably, the glutathione dependent anti oxidative system is second-rate in processes of cells protecting from the consequences of oxidative stress.

\section{REFERENCES}

Bessonova V.P.: 2006. Heavy metals influence on plants photosynthesis. DSAU, Dnepropetrovsk.

Beutler E. - Duran O. - Kelly B.U.: 1963. The definition of glutathione in blood. J. Lab. Chim. Med., 61: 5. 882-886.

Bishnoi N.R. - Sheoran I.S. - Singh R.: 1993. Influence of Cd and Ni on photosynthesis and water relations in wheat leaves of different insertion level. Photosynthetica, 28: 3. 473-479.

del Rio L.A. - Copras F.J. - Sandalio L.M. - Palma J.M. - Gomes M. - Barroso J.B.: 2002. Reactive oxygen species, antioxidant systems and nitric oxide in peroxisomes. J. Exp. Bot., 53: 372. 1255-1272.

Foyer C.H. - Lopez-Delgado H. - Dat J.F. - Scott I.: 1997. Hydrogen peroxide- and glutathione-associated mechanisms of acclimatory stress tolerance and signalling. Physiologia Plantarum, 100. 241-254.

Gryshko V.M. - Syshchykov D.V.: 2002. A method of the glutathione reduced form determination in the plants vegetative organs. The Ukrainian Biochemical Journal, 74. 123-124.

Gryshko V.M. - Syshchykov D.V.: 2002. To the method of thiol groups maintenance determination (glutathione reduced form) in plants. Visnyk of Dnipropetrovsk University. Biology. Ecology, 10: 1. 190-193.

Hippeli S. - Elstner E.F.: 1996. Mechanisms of oxygen activation during plant stress: biochemical effects of air pollutants. J. Plant Physiol., 148. 249-257.

Ilkun G.M.: 1978. Air pollutants and plants. Naukova Dumka, Kiev.

Kangasjarvi J. - Talvinen J. - Utriainen M. - Karjalainen R.: 1994. Plant defence systems induced by ozone. Plant Cell Environ., 17. $783-794$.

Kunert K.J. - Hofer G.: 1987. Geben Veränderungen des antioxidativen Systems von Pflanzen Hinweise auf die Wirkung von Luftschadstoffen? Allg. Forstz., 27. 697-699.

Moral R. - Gomez I. - Navarro Pedreno J. - Mataix J.: 1994. Effect of cadmium on nutrient distribution, yield and growth of tomato grown in soilless culture. J. Plant Nutr., 17. 953-962.

Noctor G. - Arisi A.C.M. - Jouanin L.: 1998. Glutathione: biosynthesis, metabolism and relationship to stress tolerance explored in transformed plants. J. Exp. Botany, 49: 321. 623-647.

Noctor G. - Gomez L. - Vanacker H. - Foyer C.H.: 2002. Interactions between biosynthesis, compartmentation and transport in the control of glutathione homeostasis and signalling. J. Exp. Bot., 53: 372. 1283-1304.

Platonova A.A. - Kostishin S.S. - Bloshko M.M.: 1998. Content of glutathione reduced form and activity of glutathione dependent enzymes in pea shoots (Pisum sativum L.) at the action of cadmium and thallium ions. Physiology and Biochemistry of Cultivated Plants, 30: 4. 264-270.

Polle A. - Kroniger W. - Rennenberg H.: 1996. Seasonal fluctuation of ascorbate-related enzymes: acute and delayed effects of late frost in spring on antioxidative systems in needles of Norway Spruce (Picea abies L.). Plant Cell Physiol., 37: 6. 717-725.

Schupp R. - Rennenberg H.: 1988. Diurnal changes in the glutathione content of spruce needles (Picea abies L.). Plant Sci., 57. $113-117$.

Smith, I.K. - Polle, A. - Rennenberg, H.: 1990. Glutathione. In: Alscher, R.G. - Cumming, J.R. Stress responses in plants: adaptation and acclimation mechanisms. Wiley-Liss, New York. 201-215. 
Strohm M. - Jouanin L. - Kunert K.J. - Pruvost C. - Polle A. - Foyer C.H. - Rennenberg H.: 1995. Regulation of glutathione synthesis in leaves of transgenic poplar (Populus tremula x P. alba) overexpressing glutathione-synthetase. The Plant J., 7: 1. 414-145.

Taulavuori E. - Taulavuori K. - Sarjala T. - Laine K.: 1999. Polyamines and glutathione metabolism in N fertilized Scots pine seedlings during cold hardening. J. Plant Physiol., 154. 179-184.

Usmanov T.Yu. - Rakhmankulova Z.F. - Kulagin A.Yu.: 2001. Ecological plant physiology. Logos, Moscow.

Vladimirov Yu.A. - Archakov A.I.: 1972. Lipids peroxidation in biological membranes. Nauka, Moscow. 